\title{
Rancang Bangun Sistem Informasi Employee Attendance pada PT.TNT Skypak Internasional
}

\author{
Desy Apriani ${ }^{1}$, Po Abas Sunarya*2, Tinton Yuan Permono ${ }^{3}$ \\ 1, 3Program Studi Sistem Informasi Universitas Raharja \\ ${ }^{2}$ Program Studi Manajemen Retail Universitas Raharja \\ Email :1desy@raharja.info, *2abas@ raharja.info, ${ }^{3}$ tinton@ raharja.info
}

\begin{abstract}
Abstrak
Perusahaan PT.TNT Skypak Internasional merupakan Foreign Company yang berbisnis di Indonesia dan berlokasi di area bandara Soekarno-Hatta. PT.TNT Skypak Internasional berfokus di bidang ekspedisi ekspor dan impor pengiriman barang. Saat ini terdapat kendala di dalam proses absensi karyawan/Employee Attendancenya, karena masih dijalankan secara manual maka pengambilan data Employee Attendancenya memakan waktu yang lama dan tidak efisien waktu. Untuk itulah diperlukannya sebuah sistem informasi khusus Employee Attendance yang berbasis Website sebagai solusi atas kendala yang terjadi di PT.TNT Skypak Internasional. Untuk metode penelitian yang dilakukan yakni dengan Data Collecting Methods seperti Observation, Interview dan Library Research, kemudian metode analisa rancangan dengan menggunakan diagram UML dan rancangan database dengan PHP dan MySQL. Hasil penelitian paper jurnal ini yakni Rancang Bangun Sistem Informasi Employee Attendance berbasis Website untuk diterapkan pada PT.TNT Skypak Internasional.
\end{abstract}

Kata Kunci : Sistem informasi, Website, Employee Attendance.

\begin{abstract}
PT.TNT Skypak Internasional is a foreign company doing business in Indonesia and is located in the Soekarno-Hatta airport area. PT.TNT Skypak Internasional focuses on export and import freight forwarding. Currently there are problems in the employee attendance process / Employee Attendance, because it is still being run manually, so the Employee Attendance data retrieval is time consuming and time inefficient. For this reason, a website-based Employee Attendance information system is needed as a solution to the problems that occur at PT.TNT Skypak Internasional. The research method used is Data Collecting Methods such as Observation, Interview and Library Research, then the design analysis method uses UML diagrams and database design with PHP and MySQL. The research results of this journal paper are Website-based Employee Attendance Information System Design to be applied to PT.TNT Skypak Internasional.
\end{abstract}

Keywords: Information system, Website, Employee Attendance.

\section{PENDAHULUAN}

Employee Attendance (Absensi Karyawan) memegang peranan yang sangat penting dalam setiap perusahaan. Employee Attendant merupakan List kehadiran yang dimiliki perorangan, dalam hal ini: Karyawan, sebagai bukti bahwa karyawan tersebut telah menunaikan kewajibannya sebagai pekerja pada waktu kerja setiap harinya sesuai dengan ketetapan perusahaan tempatnya bekerja. Employee Attendance biasanya dijalankan before and after activity dalam sebuah pekerjaan rutin yang diselesaikan. PT.TNT Sypak Internasional terletak di 
Bandara Internasional Soekarno Hatta tepatnya di Taman Bisnis Niaga Soewarna Tangerang. Perusahaan ini merupakan Foreign Company yang berbisnis di Indonesia dan berlokasi di area Bandara Internasional Soekarno Hatta tersebut. PT.TNT Skypak Internasional bergerak di bidang ekspedisi ekspor dan impor pengiriman barang. PT.TNT Skypak Internasional memiliki beberapa departemen salah satunya operational warehouse. Operational warehouse adalah staf gudang yang bertugas untuk menyiapkan barang-barang ekspor dan impor. Perusahaan tersebut memiliki banyak karyawan. Dalam sistem Employee Attendancenya masih menggunakan manual yaitu dengan menandatangani daftar hadir, sehingga saat pembuatan laporan akan berserakan atau tercecer dengan file lain dan memperlambat proses kerja. Dikarenakan hal tersebut maka dibutuhkan Sistem informasi Employee Attendance yang dirancang khusus berbasis website untuk diterapkan di PT.TNT Skypak Internasional yang berguna untuk dapat meminimalisir kesalahan dalam Employee Attendance Report dan mempercepat proses kerja serta meningkatkan kinerja di PT.TNT Skypak Internasional ini.

\section{TINJAUAN PUSTAKA}

Penelitian paper jurnal ini memiliki beberapa literatur hasil tinjauan pustaka yang diperoleh dari berbagai sumber dengan teori-teori sebagai berikut :

\section{Sistem Informasi}

Sistem Informasi merupakan "A set of subsystems that are interconnected and form one unit, integrate and cooperate with one another in certain ways to perform data processing functions that produce output in the form of information as the basis for making a decision ". [1]

\section{Employee}

Employee atau karyawan adalah individu yang dipekerjakan oleh suatu perusahaan atau instansi yang memungkinkan produktivitas dalam perusahaan atau instansi tersebut tetap terjaga.[2]

\section{Attendance}

Attendance atau absensi adalah "Attendance document containing a list of names, time of attendance both from the time of arrival and time of return, as well as information as a guide for calculating salary payments". [3]

\section{LITERATURE REVIEW}

Literature Review penelitian paper jurnal ini yakni sebagai berikut :

1. Penelitian yang dilaksanakan oleh Rully Roosdianto, dkk, dengan paper berjudul "Design and Build an Online Employee Attendance Information System Application". Penelitian ini bertujuan untuk :"Make it easier for employees to do attendance and at the same time be able to monitor their attendance records. It is hoped that this webbased system can provide convenience in the process of attendance, data search, and attendance recap calculations, and reduce the risk of loss and errors in recording attendance data". [4]

2. Penelitian yang dilaksanakan oleh Kennedi Sianturi dan Hadion Wijoyo, dengan paper berjudul "Design of Web-Based Payroll and Attendance Information System for Megara Hotel Pekanbaru Employees". Penelitian menjelaskan bahwa: In this study, the system used is still using the conventional way, namely by taking notes on bookkeeping and assisted by Microsoft Excel, so that the employee payroll process is not effective and efficient. From these problems raised the idea to create a web-based information system, in which it can perform computerized employee payroll management which is expected to facilitate the process of employee payroll and employee attendance processes.[5] 
3. Penelitian yang dilaksanakan oleh Nova Rio, dkk, dengan paper berjudul "Design of Employee Attendance Information System at PT. San Andreas Mandiri Bekasi”. Pada penelitian ini dalam perancangan sistemnya bertujuan untuk "To be able to minimize the error rate of decision making related to the employee attendance system, because the system is still manual, starting from attendance to making reports for absences, making it possible when the process takes place there are errors in recording, inaccurate reports made and delays in processing the necessary data". [6]

4. Penelitian yang dilaksanakan oleh Andri Zulfian, dkk, dengan paper berjudul "Design and Build a Computerized Attendance System and Employee Bonus Calculation at CV Persada Ilmu". Tujuan penelitian paper ini yakni Calculating/menghitung gaji dan bonus karyawan untuk dibuatkan laporan keuangannya, ini dilakukan karena sistem yang berjalan saat ini masih ditemukan kendala dalam sistem penggajian dan perhitungan bonus karyawan, seperti perhitungan gaji dan bonus yang masih manual, maka diperlukan sistem yang terkomputerisasi yang diharapkan dapat mempermudah dalam proses absensi maupun proses perhitungan gaji dan bonus karyawannya.[7]

5. Penelitian yang dilaksanakan oleh Gita Suci Lestari dan Triuli Novianti, dengan paper berjudul "Perancangan Aplikasi Sistem Absensi Karyawan di PT. XYZ ". Pada penelitian ini menjelaskan: "Dalam proses sistem istirahat karyawan yang masih manual yang menyebabkan kebocoran waktu dan pelanggaran lainnya. Tujuan dari penelitian ini adalah merancang dan membuat aplikasi absensi karyawan pada PT. XYZ didasarkan pada nomor id karyawan dengan sistem istirahat kerja sehingga dapat mengurangi tingkat kesalahan dan kebocoran waktu selama proses pencetakan waktu istirahat ".[8]

\section{METODE PENELITIAN}

Research Methods dalam penelitian paper jurnal ini terdiri dari beberapa metode, seperti dibawah ini :

\section{Metode Data Collecting/Pengumpulan Data}

Metode Data Collecting/pengumpulan data adalah, sebagai berikut :

1. Observation Methods/Metode Pengamatan Langsung Peninjauan langsung ke PT.TNT Skypak Internasional yang terletak di Taman Bisnis Niaga Soewarna Tangerang. Untuk mendapatkan gambaran lengkap tentang aktivitas perusahaan tersebut. Observasi dilakukan terhadap sistem atau kegiatan yang berkaitan dengan sistem absensi di PT.TNT Skypak Internasional yang terletak di Taman Bisnis Niaga Soewarna Tangerang.

2. Interview Methods/Metode Wawancara

Metode wawancara disini yakni adanya sesi tanya jawab kepada Bpk. Koko Widiatmo sebagai Supervisior Operational Warehouse PT.TNT Skypak Internasional.

3. Library Research/Studi Pustaka

Studi pustaka berarti melakukan penelitian ke perpustakaan dengan tujuan agar diperolehnya sumber data original dan ilmiah yang berasal dari books dan literatur lainnya yang membahas mengenai Employee Attendance. Selain itu juga mengambil sumber studi pustaka yang berasal dari Jurnal-jurnal nasional. 


\section{Metode Desain/Perancangan}

Metode perancangan pada penelitian paper jurnal ini sebagai berikut: Untuk analisa rancangan menggunakan diagram $U M L$, Untuk pembuatan basis data/database dan program menginduk kepada List kebutuhan Stakeholder pada elisitasi. Bahasa pemograman yang digunakan adalah PHP serta basis data/database yang digunakan yakni MySQL. Untuk software pendukung yang digunakan yakni menggunakan Macromedia Dreamweaver dan model rancangannya menggunakan UML tools yakni Visual Paradigm versi 6.4.

\section{Metode System Implementation/Implementasi Sistem}

Metode yang digunakan untuk menerapkan perancangan rancangan sistem dengan cara membuat program, dalam membentuk prototype.

\section{HASIL DAN PEMBAHASAN}

Hasil dan pembahasannya didalam Employee Attendance ini digambarkan pada Usecase diagram dalam UML dimana Actor Admin yang diusulkan digambarkan pada Gambar 1 dibawah ini :

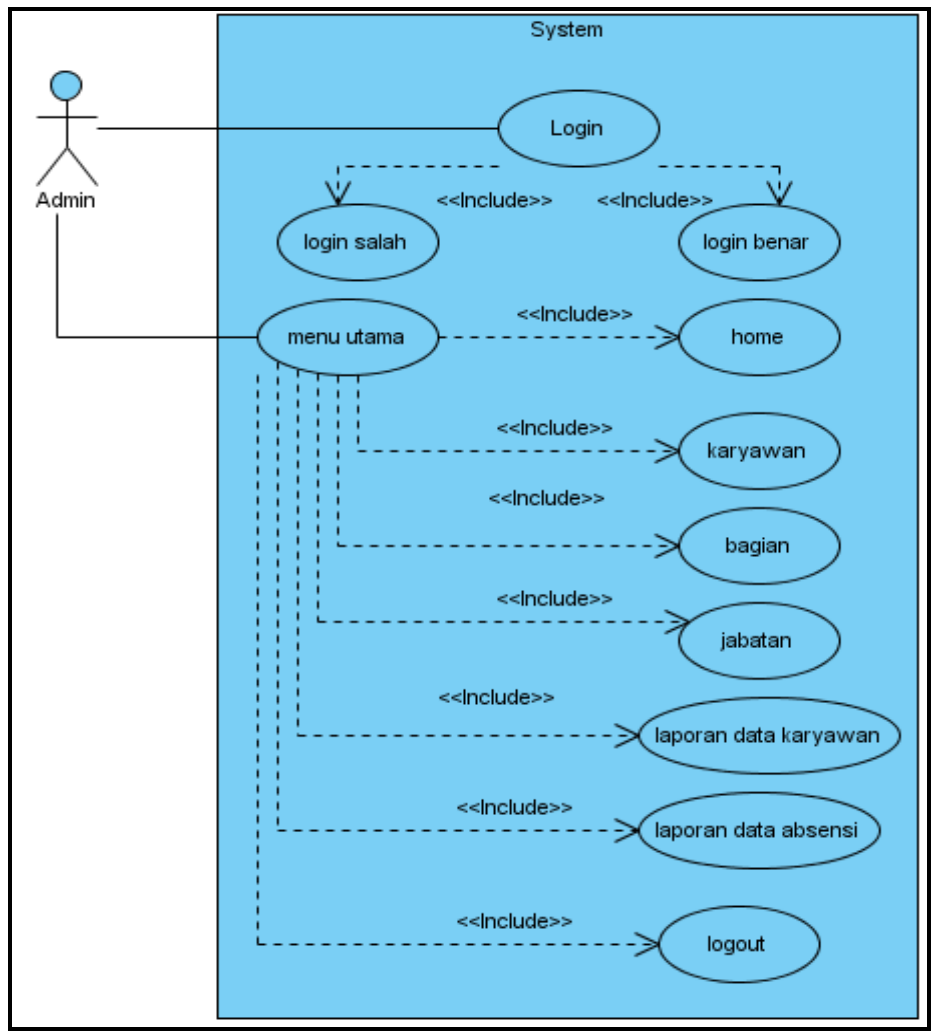

Gambar 1. Use Case Diagram pada Actor Admin yang diusulkan

Terlihat pada gambar 1 diatas, Use Case Diagram untuk Actor Admin yang diusulkan dapat dijabarkan dengan keterangan sebagai berikut :

1. 1 (satu) Sistem yang merangkum semua kegiatan Employee Attendance. 
2. 1 (satu) Actor yaitu: Admin.

3. 2 (dua) Use Case yakni: Login dan juga Menu Utama.

4. 11 (sebelas) Include yang menspesifikasikan kegiatan yang dijalankan oleh Admin.

\section{Activity Diagram yang diusulkan}

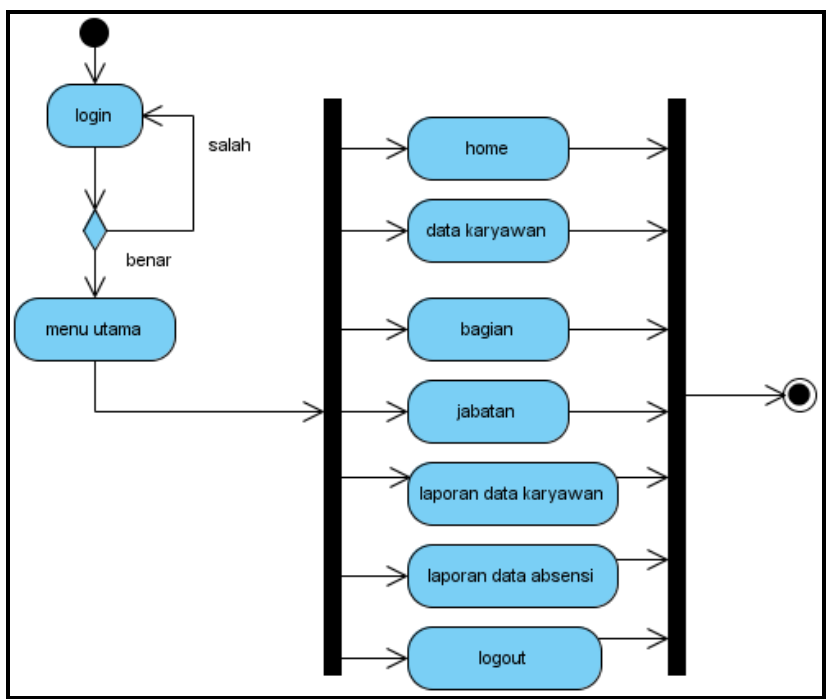

Gambar 2. Activity Diagram Admin yang Diusulkan

Terlihat pada gambar 2 diatas, Activity Diagram Admin yang diusulkan dapat dijabarkan sebagai berikut:

1. 1 (satu) Initial Node Object sebagai awal kegiatan.

2. 2 (dua) Fork node sebagai penghubung/relasi kegiatan.

3. 1 (satu) Decision Node sebagai pemilihan kondisi Benar atau Salah.

4. 9 (Sembilan) Action yaitu sebagai aktivitas yang berjalan di Activity Diagram Admin.

\section{Sequence Diagram yang diusulkan}

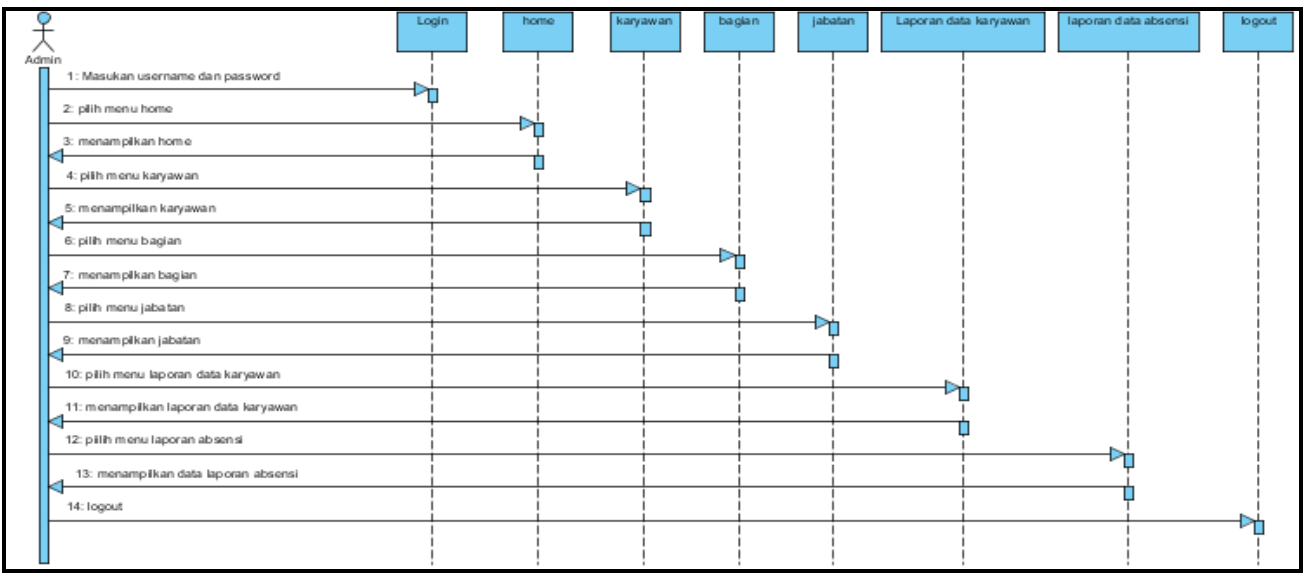

Gambar 3. Sequence DiagramAdmin yang Diusulkan 
Terlihat pada gambar 3 diatas, Sequence Diagram Admin Absensi yang diusulkan dapat dijabarkan sebagai berikut:

1. 1 (satu) Actor yaitu Admin

2. 8 (delapan) Lifeline yang berarti interface untuk saling berinteraksi

3. 14 (empat belas) Message yang terintegrasi antara Actor, Lifeline dan Decision.

\section{Class Diagram Sistem yang Diusulkan}

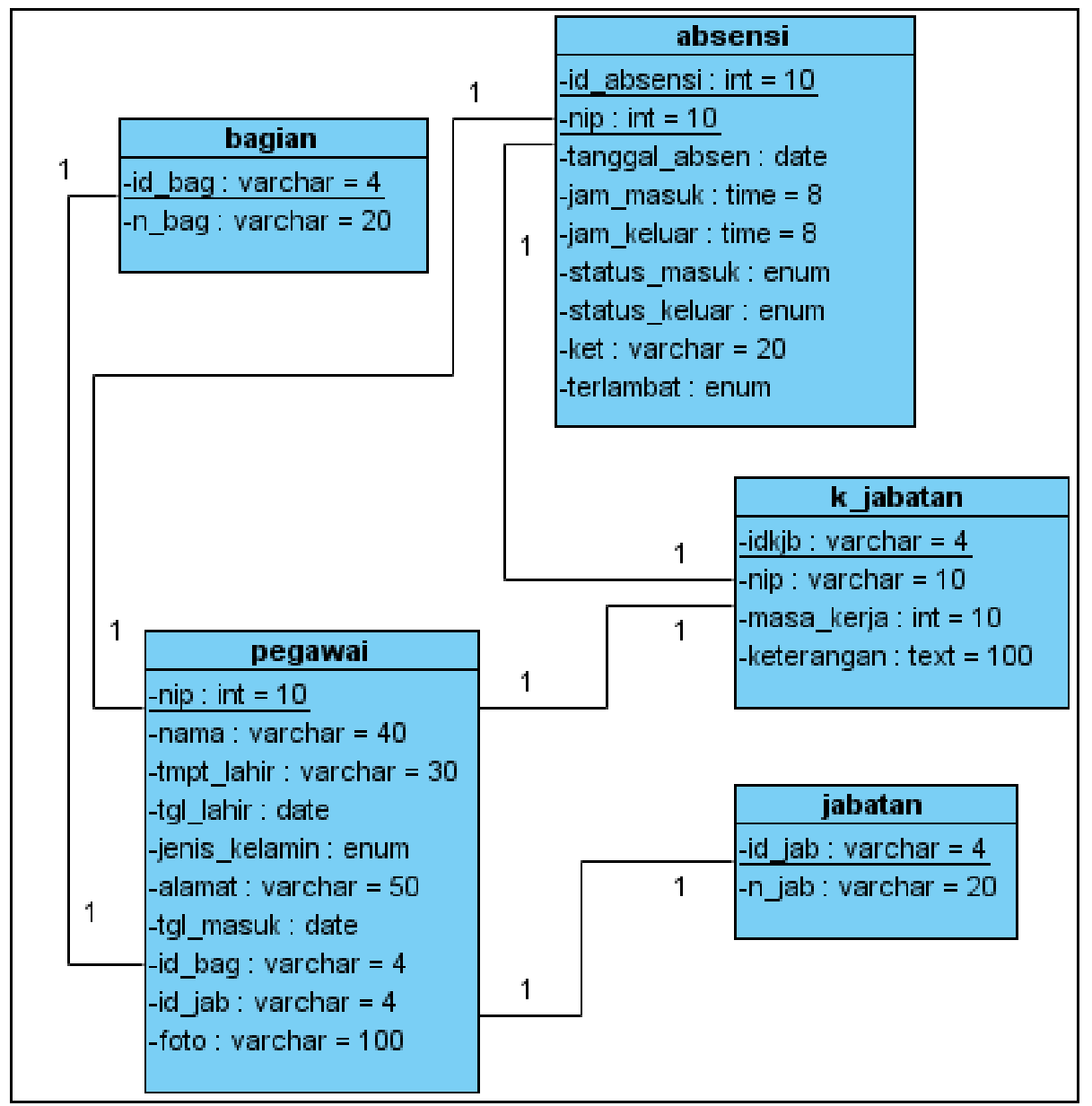

Gambar 4. Class Diagram yang Diusulkan

Terlihat pada gambar 4 diatas, Class Diagram yang diusulkan dapat dijabarkan sebagai berikut :

1. 5 (lima) Class diagram usulan yang berisi table-tabel yang didalamnya terdapat atribut yang terlibat di PT.TNT Skypark Internasional.

2. 5 (lima) Association yakni sebagai relation table-tabel pada class diagram dengan keterangan operation table yang bervariasi. 


\section{Tampilan Layar}

Tampilan layar pada penelitian paper jurnal ini digambarkan sebagai berikut :

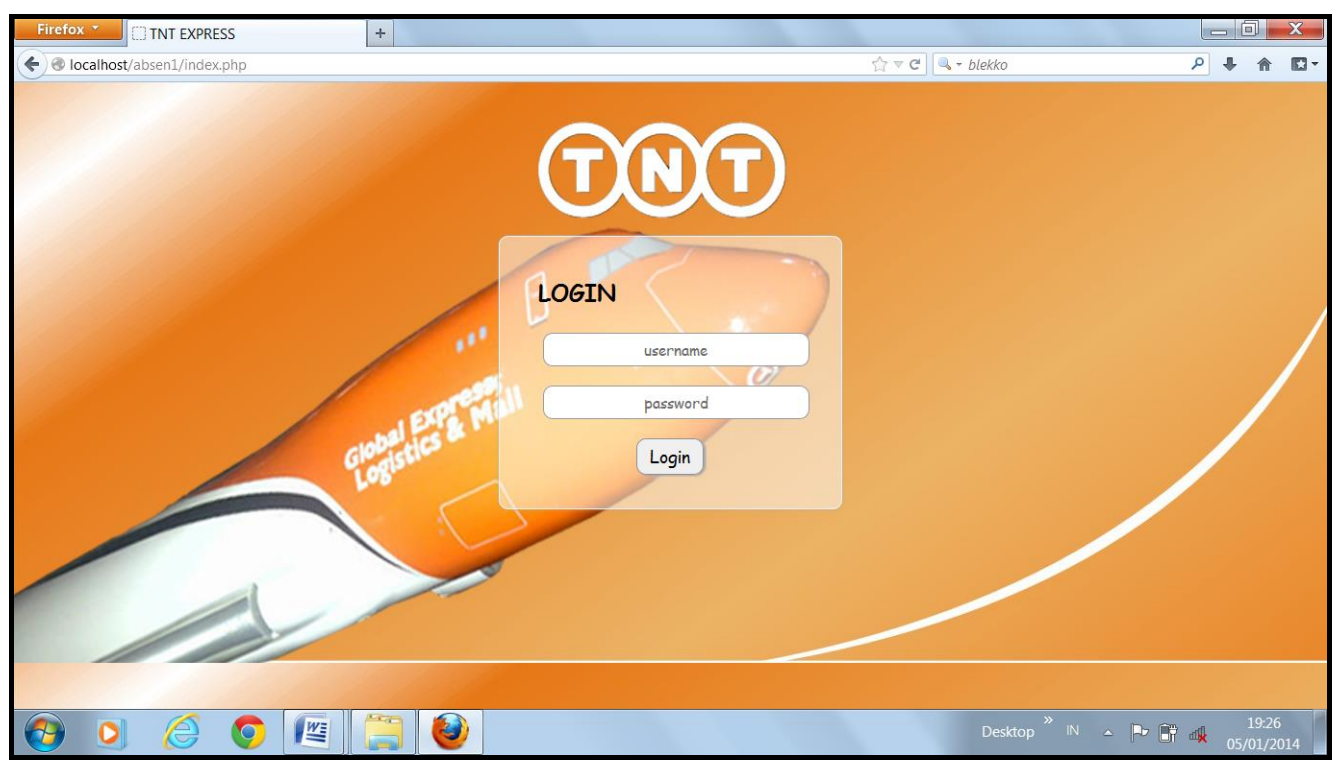

Gambar 5 TampilanMenu Login

Pada gambar 5 diatas tampak tampilan menu Login yang berisi Username dan Password yang bisa diakses oleh User.

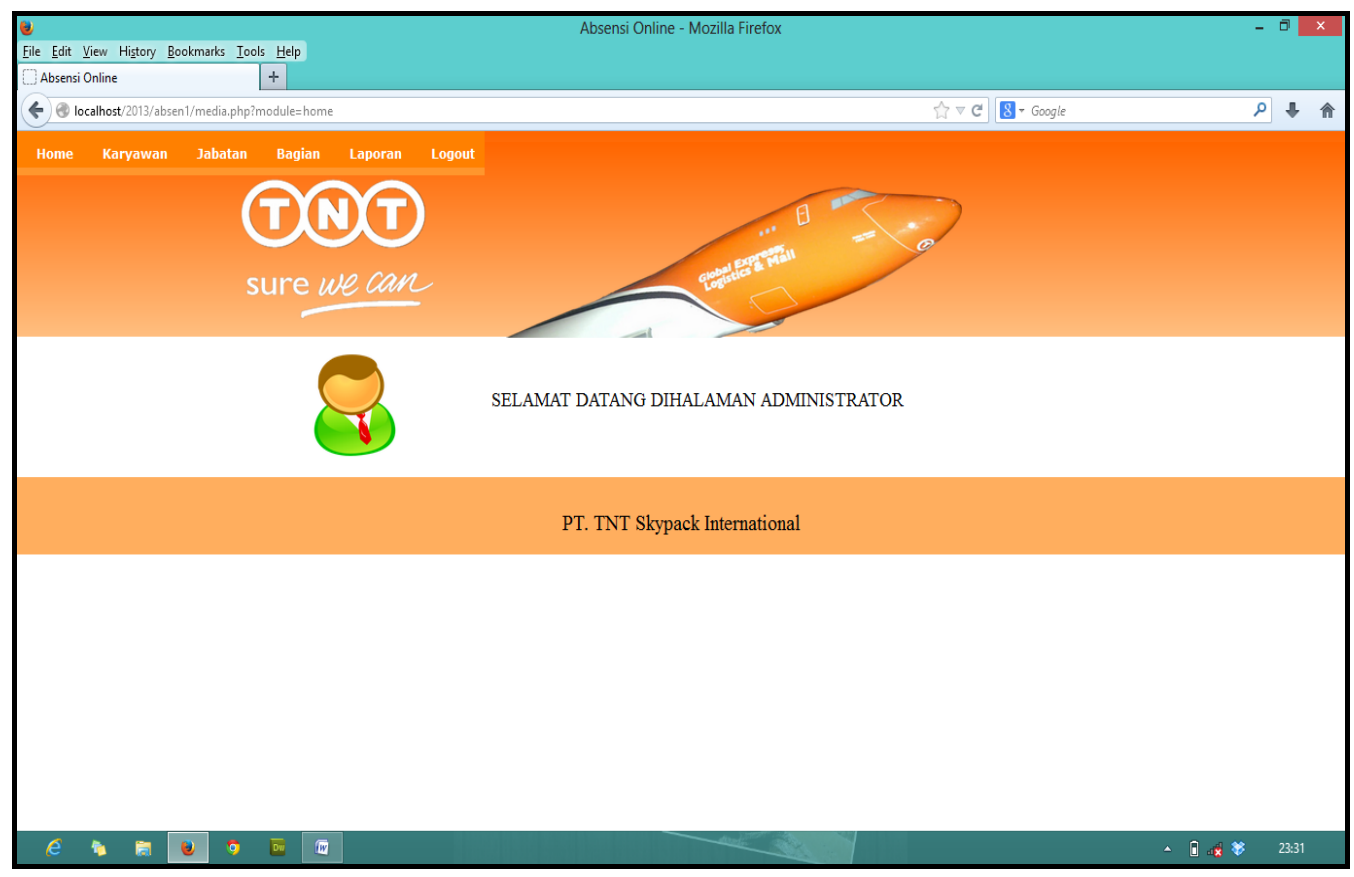

Gambar 6. Tampilan Menu Home

Pada gambar 6 diatas tampak tampilan menu Home yang terdapat tulisan "Selamat Datang dihalaman Administrator" PT. TNT Skypak International. 


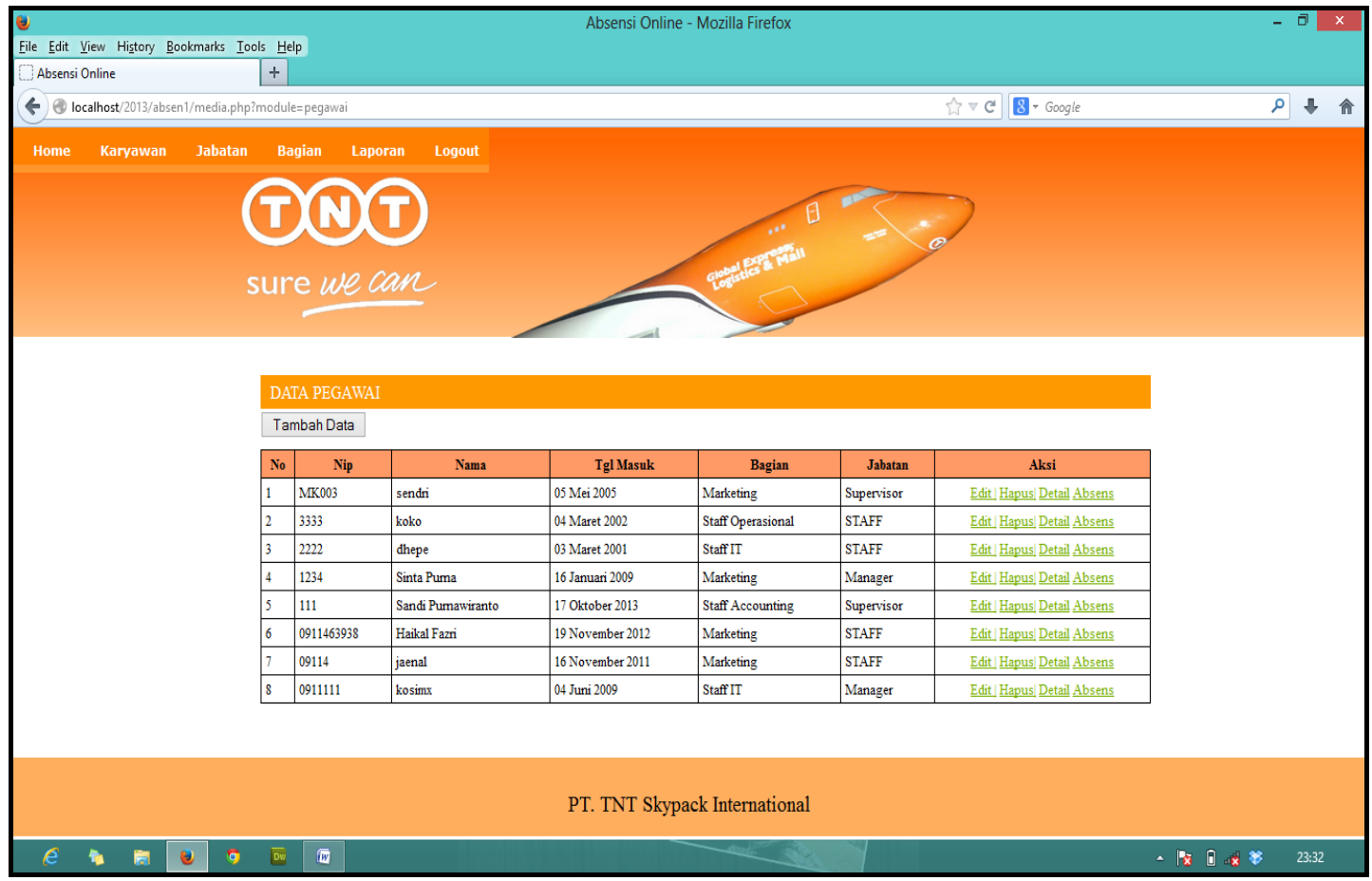

Gambar 7.Tampilan data pegawai

Pada gambar 7 diatas tampak tampilan Data-data para pegawai PT. TNT Skypak International dalam tabel yang berisi No, NIP, Nama, Tgl.Masuk, Bagian, Jabatan dan Aksi.

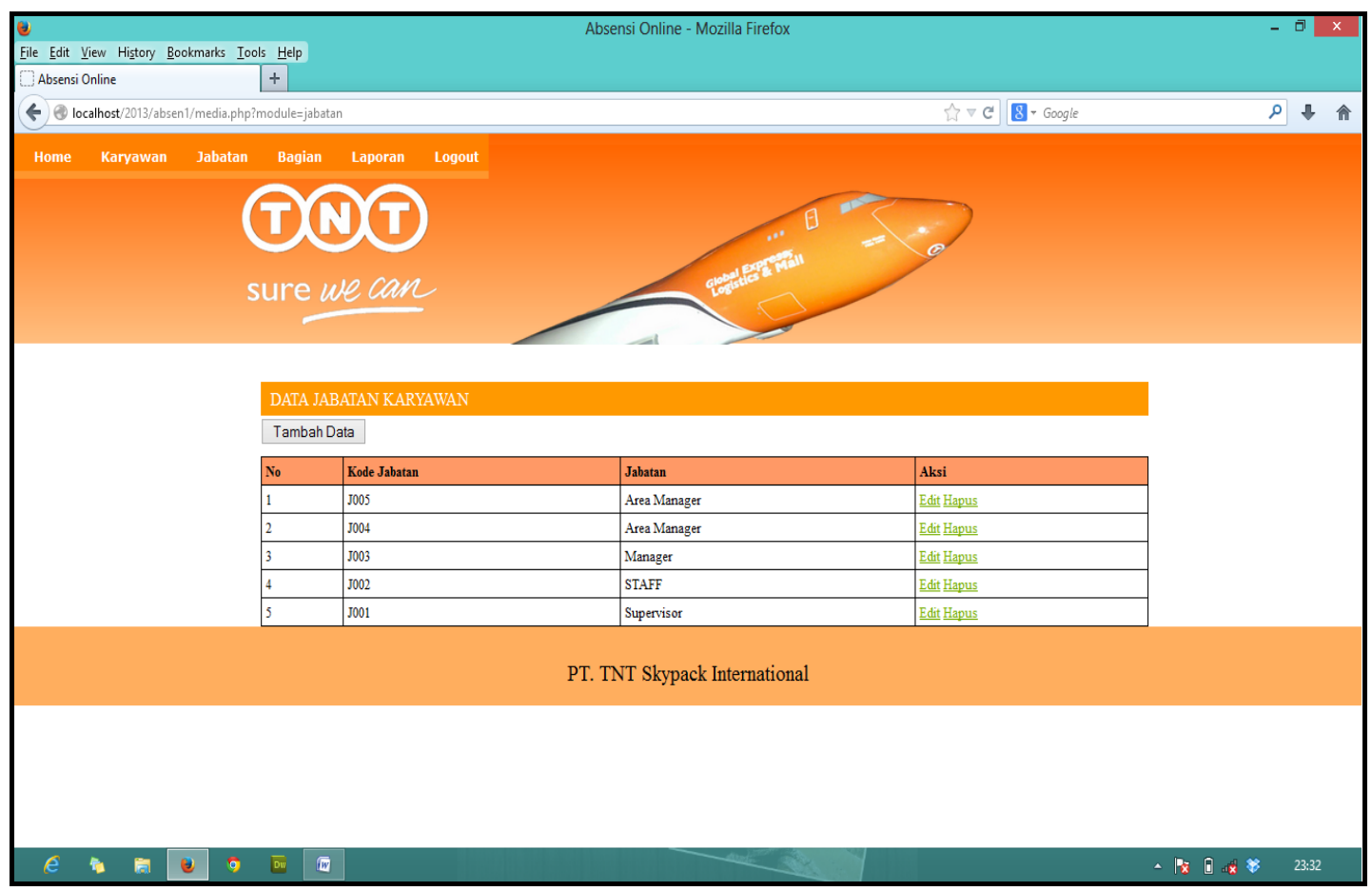

Gambar 8. Tampilan menu jabatan karyawan 
Pada gambar 8 diatas tampak tampilan menu jabatan karyawan dalam tabel yang berisi No, Kode Jabatan, Jabatan dan Aksi.

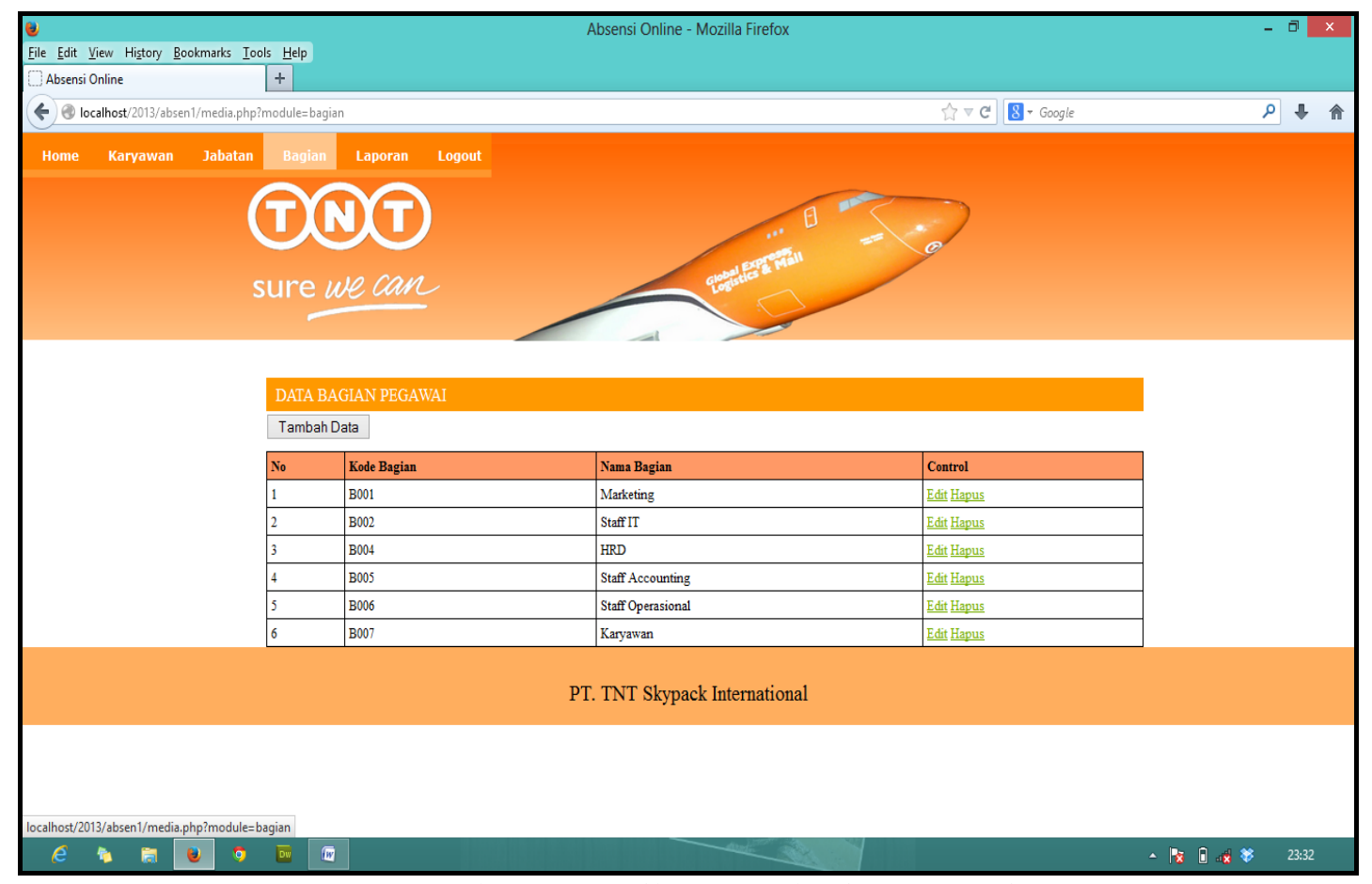

Gambar 9.Tampilan menu bagian pegawai

Pada gambar 9 diatas tampak tampilan menu bagian pegawai dalam tabel yang berisi No, Kode Bagian, Nama Bagian dan kolom Control.

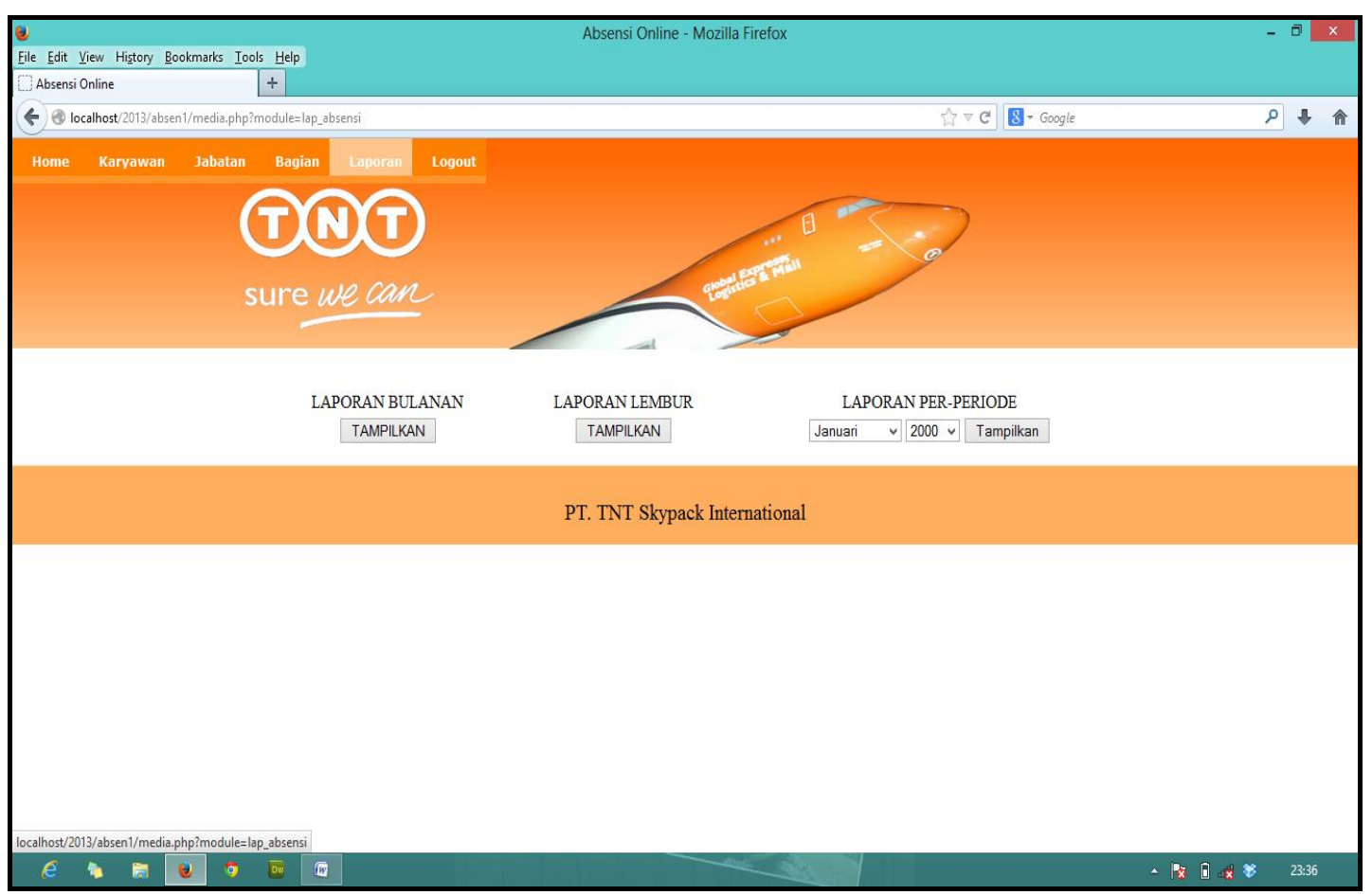

Gambar 10.Tampilan menu laporan 
Pada gambar 10 diatas tampak tampilan laporan-laporan yang terdiri atas Laporan Bulanan, Laporan Lembur dan Laporan Per-Periode yang masing-masingnya memiliki tombol 'Tampilkan'.

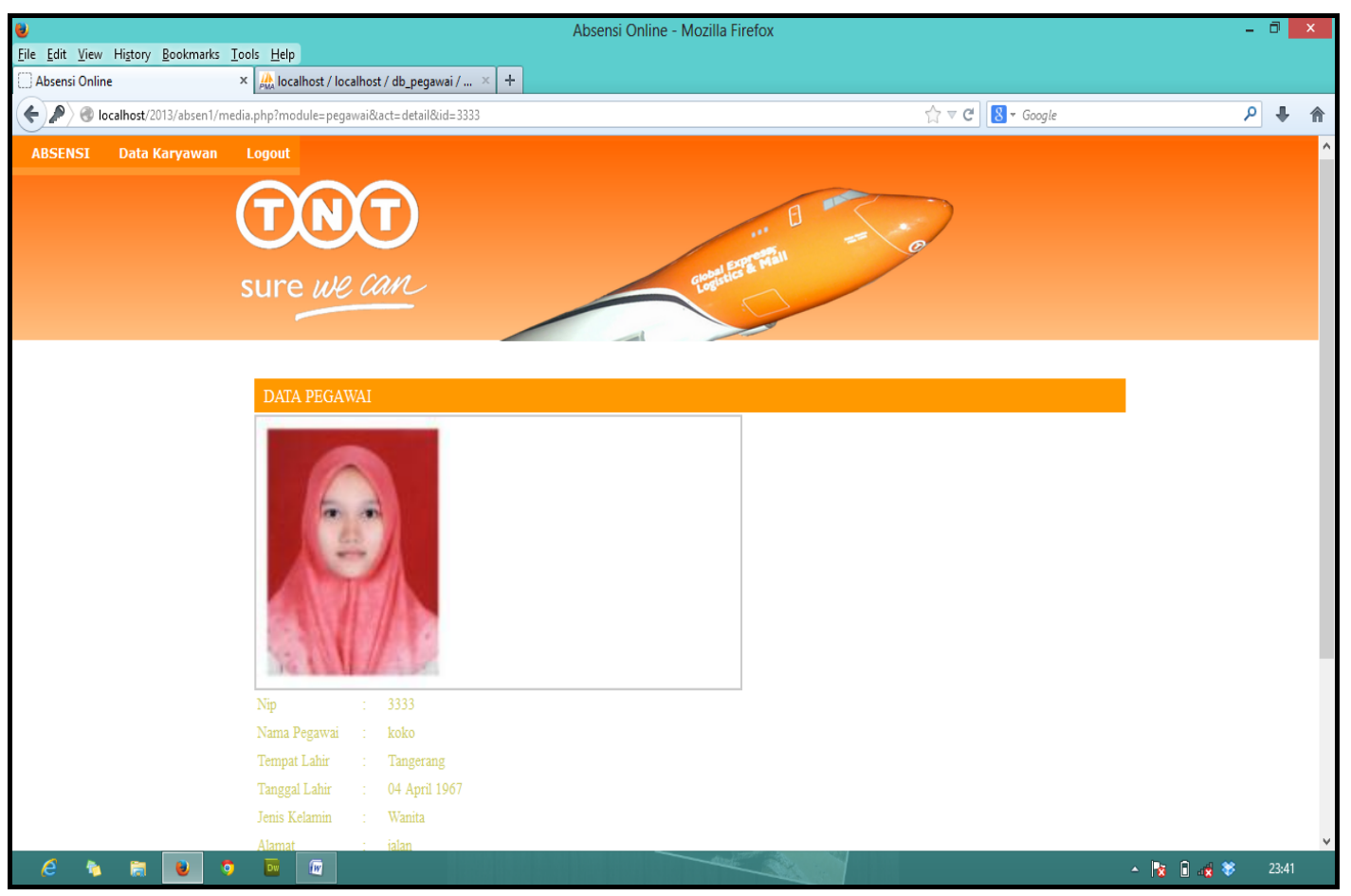

Gambar 11.Tampilan menu data pegawai

Pada gambar 11 diatas tampak tampilan menu data pegawai yang dapat diisi dengan Foto dan data-data lain yang dapat User lengkapi.

\section{KESIMPULAN}

Kesimpulan hasil penelitian paper jurnal antara lain: Proses Employee Attendance pada PT.TNT Skypak International saat itu masih menggunakan manual dan tidak efisien waktu. Terdapat kendala dalam proses Employee Attendance-nya yakni pada saat memasukkan input data masih menggunakan Ms-Excel dengan proses penghitungan yang dilakukan Looping/ulang-ulang yang menyebabkan Employee Attendance Report yang dihasilkan menyebabkan datanya kurang akurat. Kemudian kendala lainnya yakni sering terjadi kehilangan data sehingga Employee Attendance Report yang dihasilkan tidak tepat waktu. Solusi dari kendala-kendala ini yakni dibuat dan diterapkannya sebuah rancang bangun sistem informasi Employee Attendance untuk dapat digunakan dan diimplementasikan di PT.TNT Skypak Internasional.

\section{SARAN}

Disarankan agar dalam melakukan proses Employee Attendance PT.TNT Skypak Internasional menggunakan sistem computer berbasis $W e b$ atau alat-alat digital canggih lainnya agar tidak mudah dimanipulasi oleh karyawan. Disarankan dengan adanya sistem tersebut dapat memudahkan di dalam membuat dan mengevaluasi sistem Employee Attendance agar data yang dihasilkannya dapat akurat. Disarankan bahwa sistem informasi yang dirancang bangun ini dapat diimplementasikan dan dilakukan perawatan dengan baik agar dapat digunakan secara terus menerus dan memberikan manfaat untuk PT.TNT Skypak Internasional. 


\section{DAFTAR PUSTAKA}

[1] Heriyanto. Yunahar. 2018. Perancangan Sistem Informasi Rental Mobil Berbasis Web Pada PT. APM Rent Car. Jurnal Intra-Tech, 2(2), 64-77.

[2] Pratiwi. Heny I. 2018. Pelatihan Microsoft Office Untuk Karyawan dan Kelompok PKK Kelurahan Sawah Baru Tangerang Selatan. Prosiding Sembadha, 1(1), 8-13.

[3] Mulyati, Rasyid Tarmizi, dan Angga Panugali. 2018. Sistem Informasi Berbasis Web Pada Badan Penanggulangan Bencana Daerah Kota Tangerang. Jurnal ICIT (Innovative Creative and Information Technology), 4(2), 117-127.

[4] Roosdianto. Rully, Ani Oktarini Sari, dan Arief Satriansyah. 2021. Rancang Bangun Aplikasi Sistem Informasi Absensi Karyawan Online. Jurnal INTI Nusa Mandiri, 15(2), 135-142.

[5] Sianturi. Kennedi, dan Hadion Wijoyo. 2020. Rancang Bangun Sistem Informasi Penggajian Dan Absensi Karyawan Megara Hotel Pekanbaru Berbasis Web. Jurnal Ekonomi, Akuntansi, dan Manajemen, 2(2), 56-76.

[6] Rio. Nova, Dicky Hariyanto, dan Elvi Sunita. 2019. Rancang Bangun Sistem Informasi Absensi Karyawan Pada PT. San Andreas Mandiri Bekasi. Indonesian Journal on Software Engineering (IJSE), 5(2), 34-41.

[7] Zulfian. Andri, Arif Susanto, dan Sriyono. 2021. Rancang Bangun Sistem Komputerisasi Absensi Dan Perhitungan Bonus Karyawan Pada CV Persada Ilmu. Jurnal Riset dan Aplikasi Mahasiswa Informatika (JRAMI), 2(1), 52-59.

[8] Suci Lestari. Gita, dan Triuli Novianti. 2018. Rancang Bangun Aplikasi Sistem Absensi Karyawan Pada PT. XYZ. Jurnal Komunikasi, Media, dan Informatika, 7(2), 87-93. 